\title{
NASA SYNTHETIC VISION EGE FLIGHT TEST
}

\author{
Lawrence (Lance) J. Prinzel, Lynda J. Kramer, J. Raymond Comstock, \\ Randall E. Bailey, Monica F. Hughes, Russell V. Parrish \\ NASA Langley Research Center \\ Hampton, VA
}

\begin{abstract}
NASA Langley Research Center conducted flight tests at the Eagle County, Colorado airport to evaluate synthetic vision concepts. Three display concepts (size " $A$ " head-down, size "X" head-down, and headup displays) and two texture concepts (photo, generic) were assessed for situation awareness and flight technical error / performance while making approaches to Runway 25 and Runway 07 and simulated engine-out Cottonwood 2 and KREMM departures. The results of the study confirm the retrofit capability of the HUD and Size "A" SVS concepts to significantly improve situation awareness and performance over current EFIS glass and non-glass instruments for difficult approaches in terrainchallenged environments.
\end{abstract}

\section{INTRODUCTION}

The Synthetic Vision Systems (SVS) element of the National Aeronautics and Space Administration's (NASA) Aviation Safety Program (AvSP) is striving to eliminate poor visibility as a causal factor in aircraft accidents as well as enhance operational capabilities of all aircraft. To accomplish these safety and situation awareness improvements, the SVS concept is designed to provide a clear view of the world ahead through the display of computer generated imagery derived from an onboard database of terrain, obstacle, and airport information.

The ability of a pilot to ascertain critical information through visual perception of the outside environment can be limited by various weather phenomena, such as rain, fog, and snow. Since the beginning of flight, the aviation industry has continuously developed various devices to overcome lowvisibility issues, such as attitude indicators, radio navigation, and instrument landing systems. Recent advances include moving map displays, incorporating advances in navigational accuracies from the Global Positioning System, and enhanced ground proximity warning systems. However, all of the aircraft information display concepts developed to date require the pilot to perform various additional levels of mental model development and maintenance and information decoding in a real-time environment when outside visibility is restricted.

Better pilot situation awareness during low visibility conditions can be provided by SVS displays. New technological developments in navigation performance, lowcost attitude and heading reference systems, computational capabilities, and graphical displays allow for the prospect of SVS displays for virtually all aircraft classes. SVS display concepts employ computer-generated terrain imagery, onboard databases, and precise position and navigational accuracy to create a three dimensional perspective presentation of the outside world, with necessary and sufficient information and realism, to enable operations equivalent to those of a bright, clear, sunny day regardless of the outside weather condition. The safety outcome of SVS is a display that should help reduce, or even prevent, controlled-flight-into-terrain (CFIT), which is the single greatest contributing factor to fatal worldwide airline and general aviation accidents. Other safety benefits include reduced runway incursions and loss-of-control accidents (Prinzel et al., 2000; Williams et al., 2001) in addition to significant economic benefits (Hemm, 2000).

\section{SVS Research Issues}

To provide a better definition of the concept of operations (CONOPS) of synthetic vision technology for commercial and business aircraft, a workshop resulting in a CONOPS document was held in early 2000 (Williams, et. al., 2001). The focus of this event was to obtain wide ranging input on the benefits and features which synthetic vision might incorporate. This meeting included representatives from NASA, DoD, FAA, industry professional organizations, pilots, airlines, aircraft and avionics manufacturers, airports, and academic institutions. The result of the workshop was a "shopping list" of research issues that need to be explored in developing SVS display concepts.

NASA Langley Research Center Research (LaRC) in Hampton, VA has conducted past research examining many of the issues that were identified in the CONOPS SVS workshop. Comstock, Glabb, Prinzel, \& Elliot (2001) and Stark, Comstock, Prinzel, Burdette, and Scerbo (2001) focused on the issues of retro- and forward-fit issues of display size and fieldof-view (FOV) for current and future transport aircraft. The objective of those studies was to examine whether a SVS display could be retrofitted into Electronic Flight Instruments (EFIS) Size "A" (e.g., B-757-200) Electronic Attitude Direction Indicator (EADI) and Size "D" (e.g., B-777) Primary Flight Display (PFD). A size "X" head-down display (SVSHDD) was also tested that would represent the display real estate that may be found on future aircraft. The results of those studies confirm that a SVS display could be incorporated as part of an EFIS suite and replace an EADI or PFD in providing a perspective SVS display. Furthermore, although all pilots preferred the larger display, the FOV on a smaller SVS display could be adjusted to minimize situation awareness or pilot performance penalty costs. Regardless of FOV or display size, pilots reported greater situation awareness (i.e., self-report, SA-SWORD) and had lower flight technical error (FTE) while making approaches to a non-precision runway (AVL) with the SVS display compared to the traditional EADI. 


\section{The Current Study}

Previous research was conducted in a fixed-based simulator at NASA LaRC. Although the research data indicates that an SVS display could significantly enhance situation awareness in terrain-challenged environments, these results would need to be confirmed in real-world flight tests. Data was collected during a 2000 NASA flight test on a NASA B-757-200 at the Dallas / Fort-Worth (DFW) airport. However, the objective of that flight test was to examine the efficacy of SVS for making approaches to an operationally challenged environment and not to determine the safety benefits of SVS for terrain awareness. Therefore, a NASA B-757 flight test was conducted in the Eagle County, CO Regional Airport local area (FAA airport identifier: EGE) to evaluate tactical SVS display concepts in a terrain-challenged operational environment.

EGE represents an ideal location to test the effectiveness of SVS technologies for terrain awareness and separation for approaches that puts the aircraft close to mountainous terrain. There are 2 approaches that are available for use by the major airlines flying 757s into the EGE airport: FMS 25 and FMS 07 approaches. Although the runway 25 approach is the most common approach, tailwind restrictions can require the need to make the circle-to-land 07 approach. However, as a pilot from American Airlines noted, the approach has rarely been made because of the close proximity it places the aircraft to the surrounding terrain. Furthermore, traffic into EGE is heaviest during the skiing season in which Instrument Meteorological Conditions are prevalent. The EGE airport has a special airport status and special procedures and training have been approved by the FAA for the 07 approach. The approach requires Visual Meteorological Conditions (VMC) that significantly limits the use of this end of the runway. SVS could potentially enhance the operational capability of EGE, and similar airports, in which terrain and obstacles limits IMC approaches. Therefore, the EGE area was selected to demonstrate the efficacy of SVS to maintain required navigation performance (RNP) and terrain separation during the circle-to-land 07-runway approach during Instrument Flight Rules (IFR) conditions, and confirm past simulator research.

\section{Objectives}

- Confirm the capability of SVS head-down display as retrofit concepts in glass cockpits across various SVS display sizes (Size A, Size X)

- Examine the usability / acceptability and situation awareness benefits of different methods of photo-textured and generic-textured terrain database concepts

- Determine FOV requirements for different size SVS display concept during different segments of approach to EGE

- Assess the safety benefits and actual navigation performance of the SVS concept during simulated Instrument Meteorological Conditions (IMC)

- Evaluate the use of Head-Up Displays (HUD) as a retrofit concept for non-glass cockpits
- Assess flight technical error (FTE) during manually flown landing approaches and go-around maneuvers with the SVS technologies for both runway 25 and the more operationally challenging runway 07 and verify RNP capabilities

\section{METHOD}

\section{Experimental Design}

A 3 display condition (A, X, HUD) X 2 texture (generic, photo) X 2 procedure (runways $25 \& 07$ ) mixed-factorial design was used. The flight test was designed to make comparisons across these display concepts as well as to a baseline EADI with a simulated Terrain Awareness and Warning System (TAWS). Dependent variables included flight technical error (FTE), run questionnaires, semistructured interviews, verbal protocols, and SA-SWORD.

\section{Evaluation Pilots}

Six evaluation pilots, representing 3 airlines, FAA, and Boeing, flew 12 research flights totaling 51.6 flight hours. Eighty-Seven flight test runs were conducted to evaluate the NASA display concepts with 52 being flown to Runway 07 and 35 flown to Runway 25. All participants were ATP-rated B-757 captains with operating experience at the EGE airport. Prior to deployment, all evaluation pilots received a one-day training course at LaRC to familiarize them with the SVS display concepts.

\section{Flight Test Equipment}

The flight test was conducted using the NASA LaRC B-757200 aircraft. The evaluation pilot occupied the left seat and the safety pilot occupied the right seat. Installed over the traditional EFIS instruments, a SVS research display (SV-RD) and an overhead Dassault projection HUD, driven by a Flight Dynamics Head-Up Guidance System (HGS) 4000 HUD computer, was installed on the Captain's side. The SVS-RD is a commercially available 18.1" LCD monitor and had $1280 \mathrm{X}$ 1024 horizontal pixel resolution with 900 nits of brightness. The HGS-4000 computer provides raster capability for terrain texturing and tunnel symbology while retaining high-quality stroke symbology for primary flight information (e.g., airspeed, altitude). The "background raster" was the SVS terrain; the "foreground raster" consisted of the flight instruments and tunnel ("highway-in-the-sky") symbology. The FOV of the HUD was $22^{\circ}$ vertical and $28^{\circ}$ horizontal. Figure $1 \& 2$ shows the SVS-HDD and SVS-HUD concepts, respectively. A vision restriction device covered the left-seat forward windscreen to simulate Instrument Meteorological Conditions (IMC). Also, brightness controls and a de-clutter HUD switch was available to the evaluation pilots. The pilot, through an interface on the center pedestal, could change FOV settings: Unity, $30 \mathrm{deg}, 60 \mathrm{deg}$, and $90 \mathrm{deg}$. The SVS concepts were generated using an Integraph Zx10 computer that provided video updates of $>30 \mathrm{~Hz}$ and symbology was generated using OpenGL graphics software programming language. 


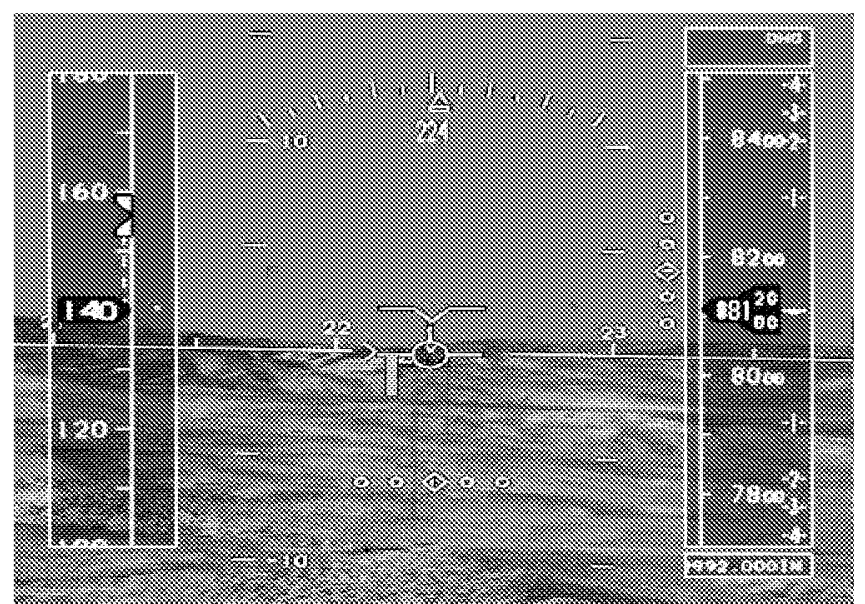

Figure 1. The SVS-Head Down Display Concept

\section{Terrain Database}

A digital elevation model (DEM) of $100 \mathrm{~nm}$ by $100 \mathrm{~nm}$ was used through the use of multi-resolution post-spacing varying between 1 and 3 arc-seconds and retaining a vertical accuracy of between 15 and 30 meters. The SVS photo-texture concept used multi-resolution imagery of between 1 and 32 meters/pixel to complete the DEM overlay and color balancing was used to create the look of photo-realism. The generictexture concept used color mapping technique, known as "elevation shading", that used Aeronautical Chart legends to create the color elevation range through the use of 12 color bands segmented into 250 meter ranges. The SVS-HUD concept for generic only used the green channel and varied the color intensities to map changes in elevation. The phototexture HUD concept used the RGB file format from the headdown photo-texture concept, masked out the red and blue channels, and converted the image back to "ECW" format.

\section{Evaluation Tasks}

The EGE airport has a "Special Airport" designation from the FAA and precision approach landing aids are not available because of terrain. Only an offset localizer with a DME is available to provide support for Localizer-DME approaches (LDA). Special Flight Management System (FMS)-based approach and landing procedures and training have been developed and certified for EGE. The evaluation tasks were developed based on these existing FMS approach procedures and comprised the FMS Runway 25 approach and Cottonwood-2 departure and the FMS Runway 25 approach with Visual Arrival to Runway 07 and KREMM Departure (Figure 4). The flight test simulated engine-out procedures during the departures by reducing thrust on both engines equally to approximate single-engine climb performance. A "follow-me" aircraft (FMA; figure 3) was resident on the SVS display that pilots used to train the velocity vector on the path guidance symbology to maintain vertical and lateral path guidance.

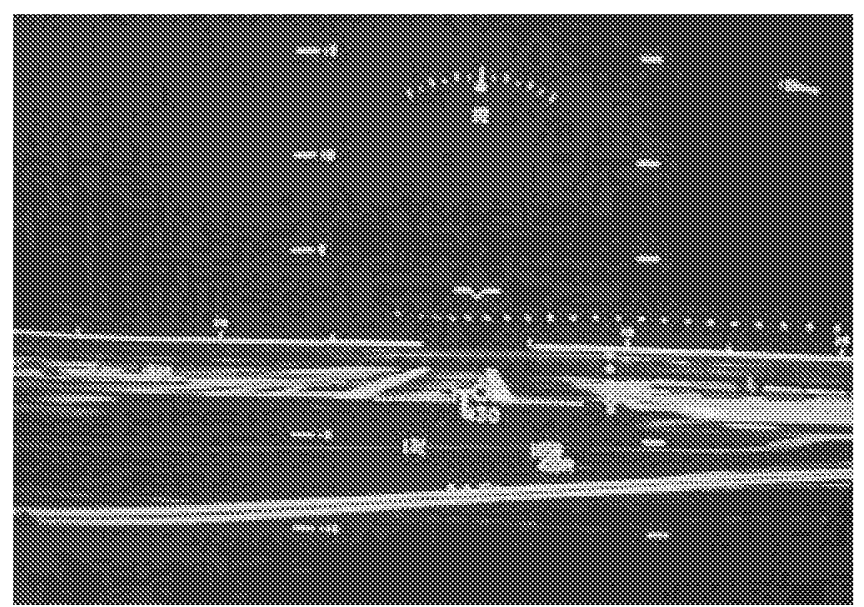

Figure 2. The SVS Head-Up Display Concept

\section{RESULTS}

A significant amount of research data was collected and analyzed and space limitations do not permit full reporting here. For further detail, please consult the NASA Technical Paper (TP) that discusses all the experimental results. Highlights of the data are described below.

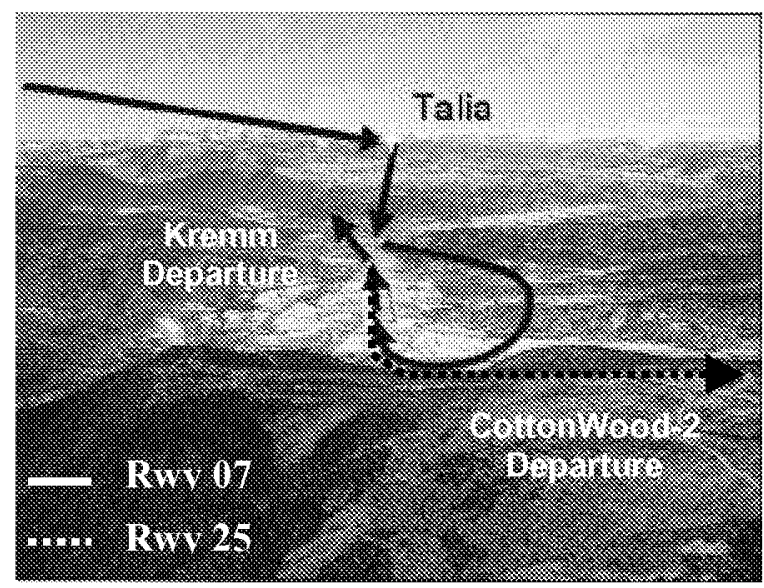

Figure 4. Runway 07 \& 25 Approaches \& Departures

\section{Post-Run Questionnaires}

Post-run questions were asked of each evaluation pilot to assess terrain awareness, while flying the approaches with the display concepts. The most significant result was that participants evaluated the Size A Photo and Size X Generic and Photo concepts to be significantly better in terms of terrain awareness over the traditional EADI, $\mathrm{F}(6,73)=2.69, \underline{p}<.01$.

\section{SA-SWORD}

Pilots were asked to complete a paired-comparison SASWORD (Vidulich \& Hughes, 1991). The responses were averaged and the overall rankings were: Photo Size X, Generic 
Size X, Photo HUD, Generic HUD, Photo Size A, Generic Size A, and Baseline EADI. The SA-SWORD data was analyzed, $\mathrm{F}(6,18)=6.98, \mathrm{p}<.01$, and revealed significant pairwise comparisons for Size $X$ Photo and Size $X$ Generic. Size $X$ Photo had significantly higher SA-SWORD ratings than all other SVS display concepts except for Size X Generic. The Size X Generic was significantly higher than all SVS display concepts with the exception of the HUD Photo.

\section{Semi-Structured Interview}

At the completion of each flight test day, all evaluation pilots participated in a semi-structured interview and completed a post-experimental questionnaire packet. Because of the number of questions asked, the complete data set cannot be addressed here. An example of a question asked: "Did the use of the NASA HUD improve your situation awareness beyond the use of the EADI w/ flight director for approach to rwy. 07? If so, please rate how much more your level of situation awareness was enhanced." The average rating (from 0 to 9), reflecting SA enhancement, was $\underline{\mathrm{M}}=7.86, \underline{\mathrm{p}}<.001$. Similar responses were found for Size $\mathrm{A}(\underline{\mathrm{M}}=7.14)$ and Size $X(\underline{\mathrm{M}}=$ 8.0) compared to EADI w/ flight director baseline condition. Therefore, the SVS concepts were reported to provide a significant enhancement of situation awareness than that provided by the traditional EADI with flight director and TAWS.

Over 80 semi-structured interview questions were asked of pilot subjects covering a number of operational and implementation issues. None of the seven pilots reported any negative responses directed toward the general SVS concept. One interesting finding concerned the use of the "follow me aircraft" guidance and velocity vector. Participants were asked to rate the ease of predicting flight path using these guidance cues for each of the SVS concepts; the average rating was 7.5 / $9.0, \underline{p}<.001$. Follow-on comments revealed that the coupled symbology allowed the pilots to remain "ahead of the aircraft" and better scan the SVS and other instruments to maintain their situational model. Moreover, pilots noted that maintaining flight path was easier with these two sets of guidance than having only a flight path tunnel. However, regardless of whether the guidance was used with or without the tunnel, pilots reported a significant enhancement of navigation awareness than that provided for by just the traditional EFIS instruments.

\section{Pilot Comments}

Video and audio recordings of each pilot were taken while they flew the two approaches and departures. These were intended to capture the verbal protocols and to verify data collection of post-run questions. Overall, pilot comments were very positive of the SVS concept. An example comment for Size A Photo Realistic was,

"I often commented to people over the years that I never ever flew a circling approach that I was ever comfortable with particularly at night. This was the first time I ever had an occasion of circling an approach with the kind of information I would love to have in a circling approach. Keeping me safe, I could see the terrain, taking me where I want to go, getting me all types of information in terms of where I am relative to the end of the runway. I mean it's the best of all possible worlds in terms of safety."

The comment reflects the majority of the comments, from highly experienced 757 line pilots that have flown the EGE approaches, that the SVS display concepts significantly enhanced situation awareness, especially for the workload intensive 07 approach. The most significant negative comments concerned the opaque nature of the SVS HUD concept and that pilots should have the ability to de-clutter (which was possible in this experiment but only for the HUD) the symbology and the terrain depiction for all SVS display concepts. Another significant issue for pilots was the presentation of obstacle data and the updating of the navigation database to ensure data integrity (NASA's goal is integrity level of $10^{-9}$ ).

\section{Evaluation Pilot Performance}

Constraints beyond the control of the authors have limited access to performance data available at time of publication (June 2002). Therefore, only the lateral path error component of flight technical error of the approach is reported here. However, the complete "path steering error" of actual navigation performance (Figure 5) and missed approached data are to be discussed at the HFES conference and results will be documented in the NASA TP final report.

Approach runs were divided into segments, graphically presented in Figure 6, and segments 1, 2, 7, and 8 comprise the 07 approach and segments $1-5$ represent the 25 approach. Segment 6 was not analyzed because the safety pilot had control of the aircraft. An ANOVA found no significant differences for texture (photo, generic) or display type (SVS only) for the 25 approach, $\mathrm{p}>.05$. Furthermore, no effect was found for texture concept for 07 approach, $\underline{p}>.05$.

Significant results, however, were found for lateral RMS for the 07 circle-to-land approach scenario for segments 2,7 , and 8. No significant result was found for segment 1 between the EADI and the SVS concepts, F $(2,10)=9.747, \underline{p}>.05$. Therefore, pilots were stabilized on approach before Talia regardless of display condition flown. However, after reaching Talia and lining up for approach (segment 2), significant differences in performance was found, $F(3,12)=16.810, \underline{p}<$ .05. Such a result was evident throughout the 07 approach for segments $7, \mathrm{~F}(3,12)=17.80, \mathrm{p}<.05$, and $8, \mathrm{~F}(3,12)=$ $110.05, \underline{\mathrm{p}}<.05$. Overall, the EADI delta, from SVS lateral RMSE, averaged 853 feet. Table 1 shows the mean values for the display concepts across segments. 


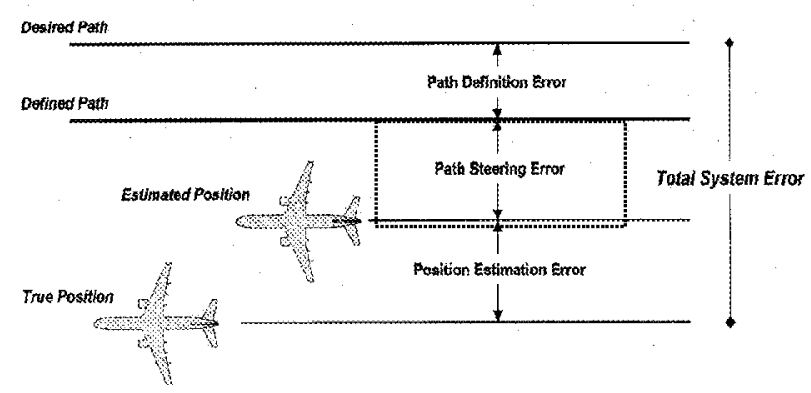

Figure 5. Required Navigation Performance Components

Table 1. Mean RMS Across 07 Approach Segments

\begin{tabular}{lllll} 
Segment & EADI & Size A & Size X & HUD \\
\hline \hline 1 & $290 \mathrm{ft}$ & $105 \mathrm{ft}$ & $97 \mathrm{ft}$ & $212 \mathrm{ft}$ \\
2 & $1106 \mathrm{ft}$ & $49 \mathrm{ft}$ & $31 \mathrm{ft}$ & $49 \mathrm{ft}$ \\
7 & $658 \mathrm{ft}$ & $36 \mathrm{ft}$ & $36 \mathrm{ft}$ & $49 \mathrm{ft}$ \\
8 & $960 \mathrm{ft}$ & $87 \mathrm{ft}$ & $97 \mathrm{ft}$ & $58 \mathrm{ft}$ \\
\hline \hline
\end{tabular}

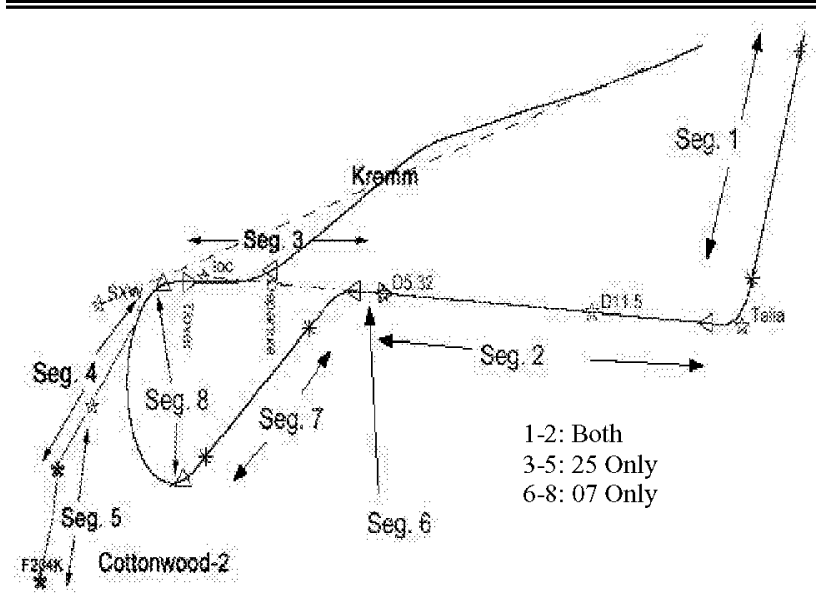

\section{DISCUSSION}

The results confirm the hypotheses that Synthetic Vision provides improved path control and situation awareness in terrain-challenged airport operating environments, and that retrofit into glass and non-glass cockpits is viable and will provide safety and performance benefits. No significant differences in performance were found between the texture concepts although pilots reported subjective preference for photo realistic for improved SA. Pilots also reported preferences for larger SVS display sizes, but again no performance differences were found. The finding may reflect the highly skilled abilities of commercial pilots to fly the approach with precision regardless of the SVS concept. However, unlike the 25 approach, the 07 EGE approach is a high workload circling maneuver and RMSE for the SVS concepts was significantly better than the EADI w/ flight director. Moreover, $100 \%$ of the pilots expressed an overwhelming preference and SA improvement for the SVS concepts over the EADI.

A number of issues, however, were uncovered and these included those regarding the use of FOV settings; minification; opaqueness of the HUD; system accuracy and integrity; human-system interaction concerns, such as trust, complacency, tunneling, and compellingness. These issues are part of the human factors list of concerns being addressed by NASA and industry partners and will be researched in an upcoming 757 flight test and ongoing laboratory research at NASA LaRC. Despite these reservations, the results of the EGE flight test confirm the findings of simulator experiments demonstrating the potential of SVS to significantly mitigate, or even eliminate, CFIT accidents. The SVS concepts described herein should be considered as part of a suite of technologies being developed (e.g., runway incursion monitors, enhanced sensors) that, together coupled with the SVS database and displays, represents the SVS concept and could considerably help meet the national aviation safety goal of reducing the accident rate by $10 \mathrm{x}$ within 25 years (NASA, 1999).

Figure 6. Approach Segments for FMS 25 \& 07 Analyses

\section{REFERENCES}

Comstock, J.R., Glabb, L. B., Prinzel, L.J., \& Elliot, D.M. (2000). Can effective synthetic vision system displays be implemented on limited display spaces? Proceedings of the $11^{\text {th }}$ International Symposium on Aviation Psychology. Ohio State University: Columbus, OH.

Hemm, (2000). Benefit estimates of synthetic vision technology. NASA Contractor Report NS002S1. NASA Langley Research Center: Hampton, VA.

National Aeronautics and Space Administration (1999). Roadmaps to the future: Strategic roadmaps in support of the three pillars and ten goals. Washington, D.C.

Prinzel, L.J., Comstock, J.R., Elliot, D., Kramer, L., Glabb, L.B., Parrish, R.V. (abstract, 2000). The NASA Synthetic Vision Systems research project. Proceedings of the $4^{\text {th }}$ Human Performance, Situation A wareness, and Automation: User-Centered Design for the New Millennium Conference Proceedings (p. 359 ). Savannah, GA: North Carolina State University, SA Technologies, \& Mississippi State University

Stark, J.M., Comstock, J.R., Prinzel, L.J., Burdette, D., \& Scerbo, M.W. (2001). A preliminary examination of pilot performance and situation awareness within a synthetic vision system. In Proceedings of the Human Factors \& Eroonomics Society $45^{\text {th }}$ Annual Meeting (pp. 40-43). Santa Monica, CA: Human Factors \& Ergonomics Society.

Vidulich, M.A., \& Hughes, E.R. (1991). Testing a subjective metric of situation awareness. In Proceedings of the Human Factors \& Ergonomics Society $35^{\text {th }}$ Annual Meeting (pp. 1307-1311). Santa Monica, CA: Human Factors \& Ergonomics Society.

Williams, D.H., Waller, M.C., Koelling, J.H., Burdette, D.W., Capron, W.R., Barry, J.S., Gifford, R.B., \& Doyle, T.M. (2001). Concept of operations for commercial and business aircraft synthetic vision systems. NASA Technical Memorandum TM-2001-211058. NASA Langley Research Center. 